\title{
Neuroinflammatory and Demyelinating Disorders of Childhood
}

\author{
Maryam Nabavi Nouri and E. Ann Yeh
}

\subsection{Introduction}

In this chapter, we will review monophasic and recurrent demyelinating disorders in children. We will first review consensus definitions and provide an approach to the evaluation of children with first episode of acquired demyelinating disorder. We will discuss typical clinical and radiological features of these syndromes. In the second section, we will review features of recurrent demyelinating syndromes in children, focusing on clinical presentation and treatment options.

\subsection{Definitions and Classification}

Acquired demyelinating syndromes (ADS) can be defined as syndromes resulting in single (monofocal) or multiple (polyfocal) lesions originating in the central nervous system (CNS) caused by inflammatory demyelination. Monophasic events may be classified as (1) clinically isolated syndrome (CIS), characterized by monofocal or polyfocal deficits without encephalopathy, or (2) acute disseminated encephalomyelitis (ADEM), characterized by polyfocal deficits and encephalopathy. Recurrent disorders include pediatric multiple sclerosis (MS), neuromyelitis optica spectrum

\footnotetext{
M. N. Nouri

Division of Neurology, Department of Pediatrics, The Hospital for Sick Children, Toronto, ON, Canada

E. A. Yeh $(\bowtie)$

Department of Pediatrics, University of Toronto, Toronto, ON, Canada

Neurosciences and Mental Health, SickKids Research Institute, Toronto, ON, Canada

e-mail: ann.yeh@sickkids.ca
} 
Table 20.1 Acute demyelinating syndrome (ADS) classification

\begin{tabular}{l} 
Monophasic ADS: \\
$\begin{array}{l}\text { - Clinically isolated syndrome (CIS): monofocal or polyfocal deficits without } \\
\text { encephalopathy }\end{array}$ \\
\hline - Optic neuritis (ON) \\
\hline - Transverse myelitis (TM) \\
\hline - Other clinically monofocal or polyfocal ADS \\
- Acute disseminated encephalomyelitis (ADEM) \\
Recurrent ADS: \\
\hline - Neuromyelitis optica (NMO) \\
\hline Serum antibodies to myelin oligodendrocyte glycoprotein (MOG) \\
\hline Pediatric multiple sclerosis \\
\hline Recurrent demyelinating disease not otherwise specified [DD-NOS]
\end{tabular}

disorders (NMOSD), and serum antibodies to myelin oligodendrocyte glycoprotein (MOG)-associated demyelination (see Table 20.1) [1].

\subsection{Approach to a Child with Suspected Demyelination}

Any patient with new, subacute focal neurologic deficits occurring after a known infection, and in the absence of trauma, metabolic derangements, or known underlying structural abnormalities, should be suspected of having acquired CNS demyelination. In addition to detailed history and physical examination, the suggested workup for these children includes cerebrospinal fluid (CSF) and serum analysis as well as neuroimaging (Fig. 20.1). Laboratory features, suggestive of acquired demyelination, include mild to moderate CSF pleocytosis, elevated CSF protein, presence of oligoclonal bands (OCBs), and increased immunoglobulin G (IgG) index. Magnetic resonance imaging (MRI) features may include the presence of multifocal white and gray matter abnormalities, presence of spinal cord lesions, optic nerve thickening or hyperintensity on T2-weighted imaging, and the presence of enhancement of lesions after the administration of gadolinium. Specific features associated with each of the disorders will be discussed below.

\subsection{Section 1: Monophasic Demyelinating Syndromes}

Clinically isolated syndromes (CIS) include optic neuritis (ON), transverse myelitis (TM), and other isolated syndromes including those with isolated cerebellar and brainstem lesions. These disorders may be monophasic in many cases, but could also be the first presentation of a relapsing syndrome such as NMOSD or MS (see Clinical course and risk of recurrence after the first demyelinating episode). Below we review each entity separately. 


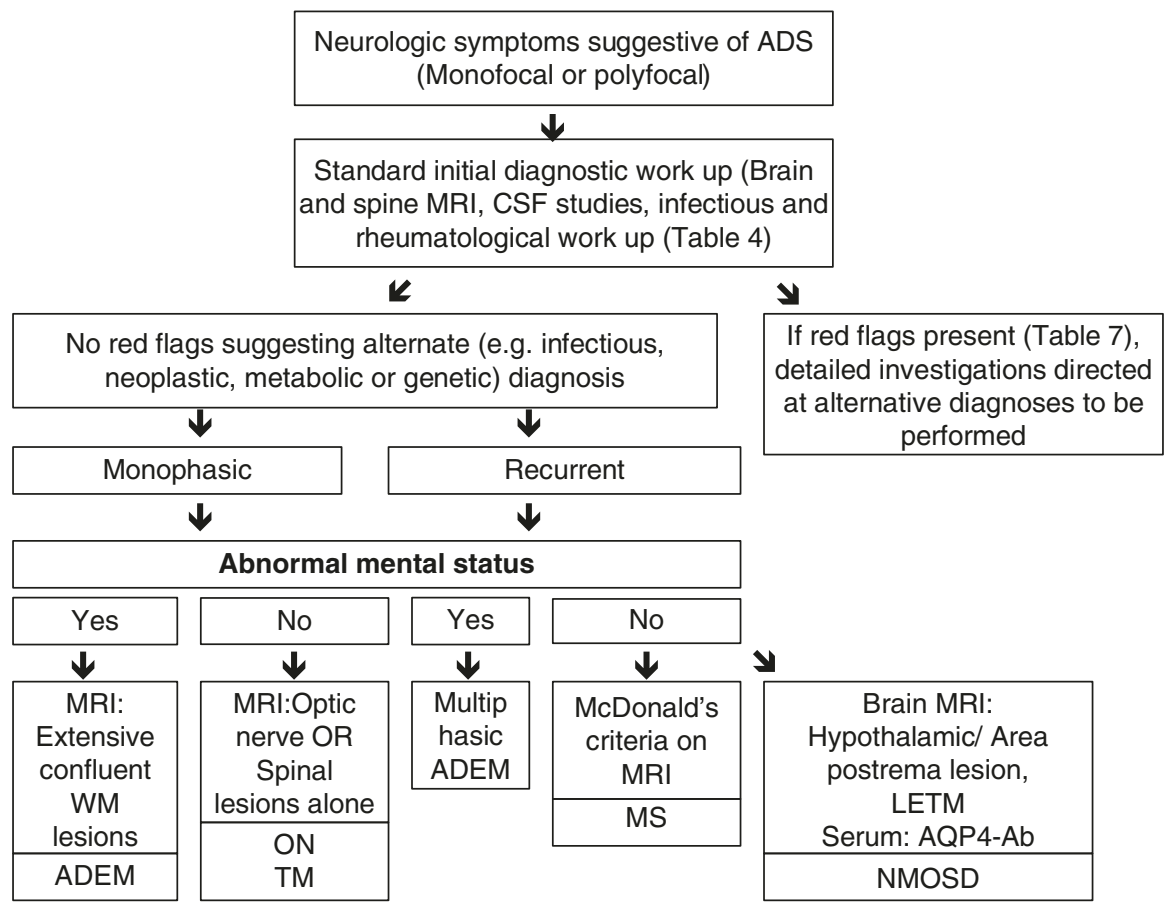

Fig. 20.1 Diagnostic approach to acquired demyelinating syndromes (ADS)

\subsubsection{Optic Neuritis}

Optic neuritis $(\mathrm{ON})$ is characterized by inflammation of the optic nerve. It may present as an isolated condition or can be associated with variety of other immunemediated CNS or systemic disorders [2]. Mean age of onset ranges from 9 to 12 years of age with an approximate 1.5:1 female-to-male ratio [3]. Its incidence is $1-5$ per 100,000/year [3]. Between 13\% and 36\% of children with an initial episode of ON are eventually diagnosed with MS [4].

\subsubsection{Clinical Features}

Common clinical features of ON include periorbital pain or headache made worse by eye movement, subacute decrease in visual acuity (VA), abnormal color vision, reduced low-contrast letter acuity, and visual field (VF) defects. Physical examination at the time of an acute event will reveal a relative afferent pupillary defect (RAPD) in unilateral cases. Initial visual acuity can range from 20/40 or better to no light perception. Close to $60 \%$ of children have a VA of 20/200 or worse [5]. 
Inflammation of the optic nerve head (papillitis) is reported in up to $64 \%$ of cases of $\mathrm{ON}$ in children [6]. Bilateral $\mathrm{ON}$ and papillitis at onset are seen in $72 \%$ of children younger than 10 years of age, in comparison to older children [5]. The absence of pain and presence of retinal exudates, retinal hemorrhages, severe disk swelling, and lack of response to treatment suggest alternative diagnosis (Table 20.2).

Table 20.2 Differential diagnosis of pediatric inflammatory demyelinating disorders

Endocrine:

- Steroid-responsive encephalopathy associated with autoimmune thyroiditis

Nutritional:

- Vitamin B12, vitamin E, or folate deficiency

- Celiac disease

- Wernike-Korsakoff

Inflammatory/autoimmune:

- Systemic lupus erythematosus (SLE)

- Acute encephalopathy with autoantibodies

- Neurosarcoidosis

- Sjögren syndrome

- Antiphospholipid antibody syndrome (APLAS)

- Behçet disease

- Isolated or primary angiitis of CNS

- Hemophagocytic lymphohistiocytosis (HLH)

- Guillain-Barré syndrome and Bickerstaff brainstem encephalitis

- Susac syndrome

- Postinfection cerebellitis

Infections:

- Neuroborreliosis (Lyme disease)

- HSV encephalitis

- HIV infection

- Tuberculosis

- Neurocysticercosis

- Neurosyphilis

- Progressive multifocal leukoencephalopathy (PML)

- Whipple disease

- Thrombotic thrombocytopenic purpura/hemolytic-uremic syndrome (TTP/HUS)

- HTLV-1

Mitochondrial:

- Myoclonic epilepsy with ragged red fibers (MERRF)

- Mitochondrial encephalomyopathy with lactic acidosis and stroke-like episodes (MELAS)

- Leber hereditary optic neuropathy (LHON)

- Leigh syndrome

- Kearns-Sayre syndrome

- DNA polymerase gamma (POLG)-related disorders 
Table 20.2 (continued)

Genetic/metabolic:

- Inborn errors of metabolism

- Amino acid and organic aciduria

- GM2 gangliosidosis

Leukodystrophy:

- Metachromatic leukodystrophy

- Adrenoleukodystrophy

- Krabbe disease

- Pelizaeus-Merzbacher disease

- Refsum disease

- Vanishing white matter

- Leukoencephalopathy with brainstem and spinal cord involvement and elevated lactate levels

- Biotin-responsive basal ganglia disease

- Wilson disease

- Fabry disease

- Alexander disease

Toxic:

- Radiation

- Chemotherapy (methotrexate, cyclosporine, cytosine-arabinoside)

- Extrapontine myelinolysis

Neoplastic:

- Lymphoma

- Astrocytoma

- Medulloblastoma

- Metastases

- Langerhans cell histiocytosis

Others:

- Migraine

- CADASIL

\subsubsection{Laboratory and Neuroimaging Features}

For optic neuritis, a basic inflammatory and infectious workup is recommended. A summary of recommended CSF and serological investigations for first-time ADS in children is listed in Table 20.3. Brain MRI is helpful for MS risk stratification. MRI features in $\mathrm{ON}$ consist of thickening of the optic nerves on T1-weighted imaging, bright T2 signal along the optic nerve or chiasm, and postgadolinium enhancement on T1-weighted imaging. Visual evoked potentials (VEPs) will show prolongation of the P100 in the acute phase. Visual field (VF) testing can be performed in children older than 7 years of age and may show an enlarged central, paracentral, or altitudinal scotoma. Optical coherence tomography (OCT) will show increased retinal nerve fiber layer thickness (RNLFT) at onset of ON if papillitis is present. In 
the chronic phase, reductions in the RNLFT will be seen, with an average reduction in RNFLT of around $25 \%$ after one episode [7]. In cases of bilateral optic neuritis or MRI features suggestive of NMOSD, aquaporin-4 (AQP4) antibody should be tested (see Sect. 20.7). A proposed relationship between serum anti-MOG antibodies and recurrent $\mathrm{ON}$ in children has also been reported [8].

Patients who present with ON and no lesions on MRI typically have a monophasic course and a favorable prognosis. A retrospective multicenter cohort study of 357

Table 20.3 Investigations for a child with suspected demyelinating disorder

\begin{tabular}{|c|c|}
\hline Investigation & Diagnostic purpose \\
\hline \multicolumn{2}{|l|}{ Neuroimaging } \\
\hline Full spine MRI with gadolinium & $\begin{array}{l}\text { MS, LETM in NMO, nerve root enhancement in } \\
\text { Guillain-Barré syndrome (GBS) } \\
\text { Vertebral body compression, disk herniation, } \\
\text { epidural hematoma, tumors, arteriovenous } \\
\text { malformation, ischemic myelopathy, atlantoaxial } \\
\text { subluxation }\end{array}$ \\
\hline Brain and orbits MRI & MS, NMO, ADEM, leukodystrophy \\
\hline \multicolumn{2}{|l|}{ CSF studies } \\
\hline CSF cell count and cytology & Inflammation, infection, and tumor \\
\hline CSF protein and glucose & $\begin{array}{l}\text { Guillain-Barré syndrome, meningitis, } \\
\text { encephalitis }\end{array}$ \\
\hline $\begin{array}{l}\text { IgG index, oligoclonal bands (paired with } \\
\text { serum) }\end{array}$ & MS, NMO, and TM \\
\hline Fungal and bacterial CSF cultures & Infections \\
\hline $\begin{array}{l}\text { CSF viral serology: } \\
\text { - Polymerase chain reaction (PCR) for } \\
\text { HSV, CMV, EBV, VZV, human } \\
\text { herpesvirus 6-7 (HHV6-7) } \\
\text { - Enterovirus, Parechovirus, West Nile } \\
\text { virus } \\
\text { - Human T-cell leukemia virus type } 1 \\
\text { (HTLV-1) }\end{array}$ & Viral and bacterial infections \\
\hline $\begin{array}{l}\text { Mycoplasma pneumoniae } \\
\text { Borrelia burgdorferi } \\
\text { Acid-fast Bacilli (AFB) } \\
\text { VDRL }\end{array}$ & $\begin{array}{l}\text { Lyme disease (seasonal) } \\
\text { Tuberculosis (TB) } \\
\text { Syphilis }\end{array}$ \\
\hline
\end{tabular}

\begin{tabular}{l|l}
\hline Serology_infectious workup & \\
\hline $\begin{array}{l}\text { Serum viral serologies: } \\
\text { - PCR for HSV, CMV, EBV, VZV }\end{array}$ & Viral and bacterial infections \\
- West Nile virus \\
$\begin{array}{l}\text { - HTLV (based on travel to endemic } \\
\text { areas only) }\end{array}$
\end{tabular}


Table 20.3 (continued)

\begin{tabular}{|c|c|}
\hline \multicolumn{2}{|l|}{ Serology_autoimтипе workup } \\
\hline Serum aquaporin-4 IgG & NMOSD \\
\hline $\begin{array}{l}\text { Erythrocyte sedimentation rate (ESR), C-reactive protein } \\
\text { (CRP), antinuclear antibody (ANA), extractable nuclear } \\
\text { antigen (ENA), double-stranded DNA, antineutrophil } \\
\text { cytoplasmic antibody (ANCA), antiphospholipid } \\
\text { antibodies, lupus anticoagulant, Anti-Ro, Anti-La, } \\
\text { Thyroid-stimulating hormone, Antithyroid peroxidase } \\
\text { (Anti-TPO) }\end{array}$ & $\begin{array}{l}\text { Systemic lupus erythematosus, } \\
\text { Sjögren syndrome, } \\
\text { antiphospholipid antibody } \\
\text { syndrome (APLAS), Behçet } \\
\text { disease, Hashimoto } \\
\text { encephalopathy }\end{array}$ \\
\hline MOG antibodies & $\begin{array}{l}\text { MOG antibody-associated } \\
\text { disease }\end{array}$ \\
\hline Angiotensin-converting enzyme level and chest X-ray & Sarcoidosis \\
\hline \multicolumn{2}{|l|}{ Serology—nutritional workup } \\
\hline $\begin{array}{l}\text { Vitamin B12, folate, vitamin E, Biotinidase, vitamin D, } \\
\text { copper, plasma amino acids, ammonia, lactate }\end{array}$ & $\begin{array}{l}\text { Nutritional and metabolic causes } \\
\text { of myelopathy }\end{array}$ \\
\hline \multicolumn{2}{|l|}{ Special tests } \\
\hline Visual evoked potentials (VEPs) & Silent demyelinating lesions \\
\hline
\end{tabular}

children with ON, followed for a median of 4 years, showed that the two strongest predictors of developing MS were the presence of CSF oligoclonal bands (seen in $80 \%$ of patients with MS and only in $15 \%$ of children with monophasic ON) and abnormal cranial MRI [9].

\subsubsection{Transverse Myelitis}

Twenty percent of children with a first episode of demyelination experience transverse myelitis. The mean age of presentation is 8 years, with a bimodal distribution (children under 5 and children 10-12 years) [10,11]. Approximately $50 \%$ of patients report a preceding infection, typically a nonspecific upper respiratory tract infection in the previous month [12]. Close to $10 \%$ of patients with acute transverse myelitis (ATM) develop MS [13].

\subsubsection{Clinical Features}

Acute transverse myelitis (ATM) is characterized clinically by acute or subacute development of neurologic dysfunction in motor, sensory, and autonomic nerves and may be accompanied by bowel and bladder dysfunction. Children may present with complete or partial cord syndromes, manifesting as patchy motor or sensory deficits with occasional bladder involvement. One of the most common initial symptoms in children is pain, which is seen in up to $60 \%$ of children at presentation [14]. Sensory findings may include positive symptoms, such as burning, paresthesias, hyperesthesia, or negative symptoms, such as numbness. Importantly, a clearly 
defined sensory level may not be evident in up to $40 \%$ of children [15]. Sphincter involvement is reported in up to $72 \%$ of children with ATM [10]. Motor symptoms are predominantly in keeping with upper motor neuron (UMN) findings, such as weakness, increased tone, and hyperreflexia in the lower extremities. Signs of spinal shock, manifesting as flaccid paresis and absent reflexes, are reported in the initial phase and may last up to 12 weeks [14]. Acute and hyperacute deficits, suggestive of a spinal cord lesion, warrant urgent spinal imaging, as an earlier intervention for vascular disorders and spinal cord compression may improve the outcome. The presence of a sensory level, radicular pain, areflexia, and failure to respond to anti-inflammatory therapies raises concern for an alternative diagnosis (Table 20.2). Diagnostic criteria have been established by the Transverse Myelitis Consortium Working Group (TMCWG) to define idiopathic ATM (Table 20.4). The utility of the TMCWG definitions in younger children is limited, as the presence of a clear sensory level is difficult to discern on physical examination and gadolinium-enhancing lesions may not be present in this age group [16].

\subsubsection{Laboratory and Neuroimaging Features}

In ATM, MRI lesions reveal T1-isointense and T2-hyperintense signals involving the gray matter and neighboring white matter (WM) and may enhance with gadolinium. Lesions may be contiguous or patchy. Longitudinally extensive TM (LETM), defined as expanding across greater than three vertebral segments, occurs in $66-85 \%$ of ATM in children. In some patients with suggestive clinical features, the initial spine MRI may be normal and should be repeated in 24-48 h after presentation [11]. While CSF pleocytosis $\left(>5 \mathrm{WBC} / \mathrm{mm}^{3}\right)$ provides supporting evidence for ATM, normal CSF results have been reported in up to $50 \%$ of pediatric patients with ATM [12]. A complete recommended workup for ADS is reviewed in Table 20.3. In patients with ATM, a higher risk of MS is seen in those with longitudinal lesions between 1 and 3 spinal segments. Similarly, the presence of CSF oligoclonal bands increases the risk for MS [17].

Table 20.4 Transverse Myelitis Consortium Working Group (TMCWG) definition of acute transverse myelitis (ATM) [16]

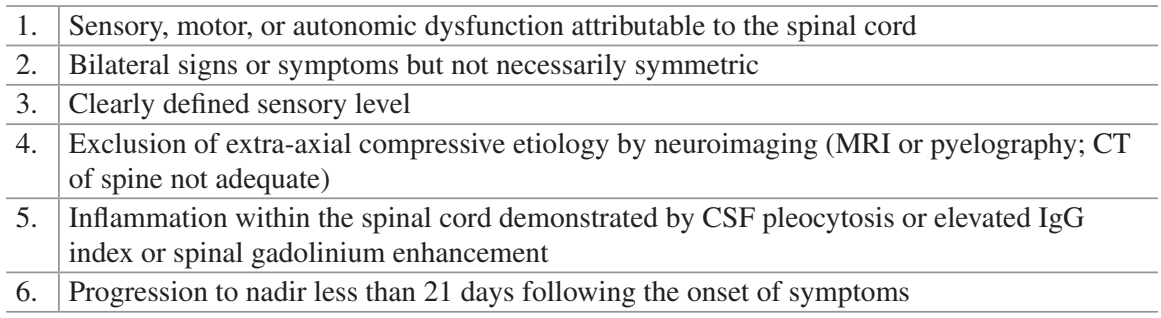

If none of the inflammatory criteria is met at symptom onset, repeat the MRI and lumbar puncture evaluation between 2 and 7 days following symptom onset to meet criteria 


\subsubsection{Acute Disseminated Encephalomyelitis (ADEM)}

ADEM is monophasic in 70-90\% of cases. Encephalopathy and multifocal brain lesions on MRI affecting the gray and white matter of the brain and spinal cord are characteristic of ADEM. Estimated incidence is $0.2 / 100,000$ in Canada [18]. The mean age of onset of ADEM in the pediatric population is reported to be $7.4 \pm 1.3$ years of age [19]. A preceding triggering event is reported in the majority of children (69\%) receiving a diagnosis of ADEM [19]. In addition, ADEM has been reported following vaccinations (postimmunization encephalomyelitis). Vaccination-associated ADEM has been observed after the measles/mumps/rubella vaccinations $[20,21]$. Two prospective studies of children with ADEM showed that $5-18 \%$ had a second attack suggesting MS [22, 23].

\subsubsection{Clinical Features}

Children with ADEM present with encephalopathy in association with multifocal neurologic deficits, which reach a nadir 4-7 days after presentation. Encephalopathy may include irritability, confusion, lethargy, and coma [24]. Prodromal symptoms can include fever, malaise, headache, nausea, and vomiting. Neurologic signs and symptoms in ADEM include long-tract signs (60-95\%), acute hemiparesis (76\%), cerebellar ataxia (20-65\%), visual loss due to optic neuritis (7-23\%), cranial nerve involvement (22-45\%), seizures (13-35\%), spinal cord involvement (24\%), and slurred speech $(5-12 \%)$ [19, 22]. Viruses that have been described in single case reports in relation to ADEM include coronavirus, coxsackie, cytomegalovirus (CMV), Epstein-Barr (EBV), herpes simplex (HSV), hepatitis A, HIV, influenza, measles, rubella, varicella zoster (VZV), West Nile, and more recently Zika [2529].Typically, there is a latency period of 7-14 days between a febrile illness and the onset of neurologic symptoms. More aggressive variants of ADEM have been described in the literature, including acute hemorrhagic leukoencephalitis and acute necrotizing encephalopathy of childhood (ANEC).

Clinical features can often help differentiate between ADEM and MS [26]. ADEM usually follows a prodromal viral illness and can be associated with fever. ADEM usually produces widespread central nervous system disturbance with impaired consciousness and/or encephalopathy, while MS typically has a relapsing-remitting course. Disease activity more than 3 months after ADEM onset is suggestive of a more chronic disorder like MS. CSF oligoclonal bands are seen most consistently in patients with MS. ADEM has a monophasic course in a majority of patients; however, multiphasic cases have been reported. As such, the International Pediatric Multiple Sclerosis Study Group (IPMSSG) proposed a consensus definition for multiphasic ADEM (Table 20.5). It is defined as two episodes consistent with ADEM separated by 3 months that can be associated with new or reemergence of prior clinical and MRI findings [22, 30-32]. Diagnosis of MS in children with prior diagnosis of ADEM requires a second non-ADEM attack together with either further MRI findings suggestive of new lesions or a third attack not meeting the criteria for ADEM. 
Table 20.5 Summary of 2012 International Pediatric Multiple Sclerosis Study Group (IPMSSG) definitions for clinically isolated syndrome, pediatric multiple sclerosis (MS), and other CNS demyelinating disorders

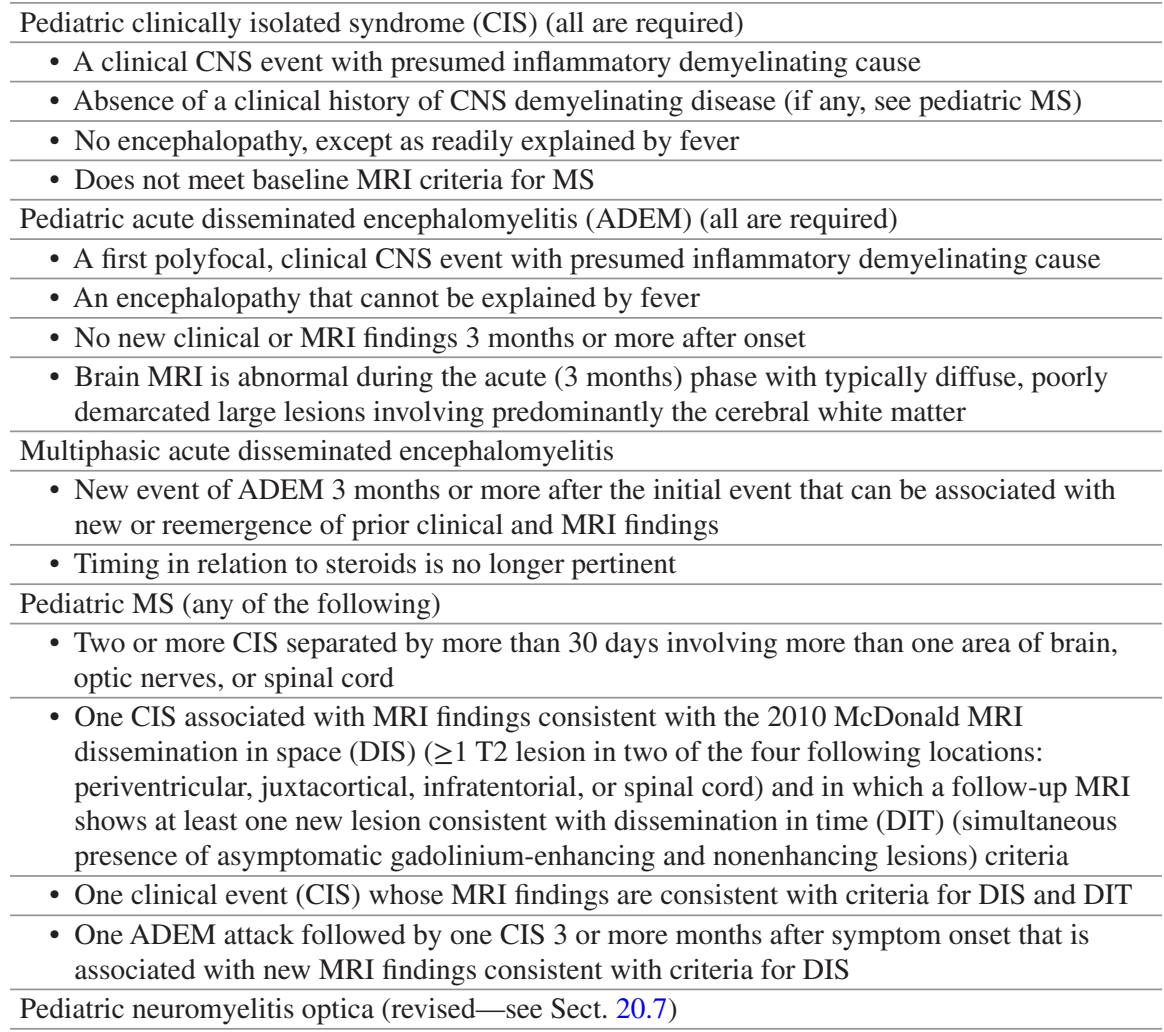

\subsubsection{Laboratory and Neuroimaging Features}

Initial diagnostic workup includes MRI of the brain and spine, serologic and CSF testing for infections in suspicious cases (Table 20.3). Lesions seen on MRI in ADEM include extensive, bilateral, asymmetric patchy areas of T2-weighted hyperintensity within the white matter, deep gray nuclei, and spinal cord. Lesions in the deep gray matter involve areas of the thalamus or the basal ganglia, which often occur bilaterally and are located at the gray-white junction [22]. Any two of the following MRI features such as (1) absence of diffuse bilateral lesion pattern, (2) presence of black holes, or (3) presence of two or more periventricular lesions can help distinguish ADEM from MS with a sensitivity of $81 \%$ and specificity of $95 \%$ [20]. CSF can be normal in up to $61 \%$ of patients with ADEM [19, 33]. The CSF examination is characterized by normal opening pressure, moderate lymphocytic pleocytosis (between 50 and 180 cells $/ \mathrm{mm}^{2}$ ) and may show elevated protein $(40-100 \mathrm{mg} / \mathrm{dL})[19,27]$. Oligoclonal bands are infrequently seen in the CSF (10\%) [34]. Despite ADEM patients commonly reporting a recent infection before their neurologic presentation, testing for viral etiologies is rarely positive (17\%) [19]. 


\subsection{Workup: First-Time Demyelination}

The differential diagnosis for children with suspected first-time demyelination is broad (Table 20.2). The workup includes neuroimaging, CSF studies, laboratory testing, and special tests (Table 20.3).

\subsection{Treatment: Acute Demyelinating Events}

In the absence of evidence-based data for the pediatric population with demyelinating disorders, most treatment recommendations are extrapolated from adult studies, case reports, case series, and retrospective analyses. There are no studies to date comparing the efficacy of the different immunomodulatory therapies in children with ADS. Acute management of patients with ADS is reviewed here.

\subsubsection{Corticosteroids}

Corticosteroids are the mainstay of treatment in demyelinating conditions, particularly in an acute relapse. High-dose corticosteroids suppress the immunologic activation associated with ADS and MS relapses via several mechanisms such as hindering the cytokine cascade, inhibiting the activation of $\mathrm{T}$ cells, facilitating the apoptosis of activated immune cells, among others [35]. The standard empiric therapy for ADS consists of high-dose corticosteroids, with $30 \mathrm{mg} / \mathrm{kg} / \mathrm{dose}$ (maximum $1000 \mathrm{mg}$ ) of methylprednisolone intravenously (IV MP) once a day for 3-5 days. In adults with optic neuritis, the optic neuritis treatment trial (ONTT) showed that IV MP hastened the recovery of vision when administered in a timely manner, and decrease in recurrence rate in the first 2 years [36]. A multicenter open-label study of 12 children and 17 historical controls with severe ATM treated with IV MP showed a significant difference in the proportion of patients treated with steroids walking independently within 1 month and achieving full recovery at 1 year compared to historical controls, with no difference in the frequency of complications between the treatment group and historical controls [37].

\subsubsection{Intravenous Immunoglobulin (IVIg)}

IVIg has an impact on inflammation by decreasing levels of cytokines, binding to antibodies against myelin, and blocking fragment crystallizable $(\mathrm{Fc})$ receptors. Additionally, it may promote remyelination. IVIg use has been reported to be of benefit in small case series in steroid-refractory acute ON and ATM cases [19]. A total of $2 \mathrm{~g} / \mathrm{kg}$ is administered, divided in one to five equal consecutive daily doses. Advantages include ease of administration, safety profile, and high tolerability [38]. Frequently reported side effects include headache and allergic reaction. Risk of thrombosis is increased with IVIg and should be considered and watched for. 


\subsubsection{Plasma Exchange (PLEX)/Plasmapheresis}

Benefits of plasma exchange occur through the elimination of pathogenic inflammatory mediators, including autoantibodies, complement components, and cytokines [39]. Case series suggest that plasmapheresis is safe in pediatric demyelinating disorders. Furthermore, in a double-blinded randomized-controlled trial of PLEX in CNS demyelinating disease where 22 patients refractory to steroids were randomized to PLEX or sham therapy, PLEX was found to have statistically significant benefits [40]. As per the American Academy of Neurology (AAN) updated guidelines, plasmapheresis may be considered in the treatment of fulminant CNS demyelinating diseases (NMODS included) that fail to respond to high-dose corticosteroid treatment (Level C) [41].

\subsubsection{Cyclophosphamide}

ATM in the context of rheumatological conditions such as systemic lupus erythematosus (SLE) has been treated with cyclophosphamide [42].

\subsection{Section 2: Recurrent Demyelinating Syndromes}

Risk of recurrence after a single demyelinating event in youth can be stratified according to the age of presentation, CSF composition, presence of antibodies such as astrocytic water channel aquaporin-4 (AQP4) antibodies, and MRI manifestations. Children under the age of 12 presenting with an ADEM phenotype and those with CIS and no brain lesions have a low risk of developing MS (1.9-3.3\%). On the other hand, children over the age of 12 presenting with multifocal lesions on brain MRI are at high risk of an eventual diagnosis of MS (60.6\%) [43]. Below, we outline clinical features of the two most recognized recurrent demyelinating syndromes.

\subsubsection{Neuromyelitis Optica Spectrum Disorders (NMOSD)}

Neuromyelitis optica spectrum disorders (NMOSD) are an increasingly recognized group of disorders characterized by the presence of AQP4 antibodies [44]. The mean age at presentation ranges from 32 to 45 years in most case series [45]. Pediatric onset of the disease is relatively rare and accounts for 3-5\% of all NMOSD cases. The frequency of AQP4 in children with inflammatory disorders of the CNS is 78\% for relapsing neuromyelitis optica (NMO) and 20\% for partial forms of NMO [46].

While AQP4 antibodies are seen in two-thirds of pediatric patients with clinical manifestations satisfying diagnostic criteria for NMOSD [44], more recently, antibodies to myelin oligodendrocyte glycoprotein (MOG) have been implicated as potentially pathological in individuals with clinical syndromes suggestive of NMOSD. Anti-MOG 
antibodies have been found to be present in children with recurrent disease who are AQP4 negative with a clinical phenotype, which includes optic neuritis, longitudinally extensive transverse myelitis, and multifocal brain lesions [47, 48]. The relevance of these antibodies for clinical practice is currently under investigation.

\subsubsection{Diagnosis}

In 2015, the International Panel for NMOSD Diagnosis (IPND) proposed revised criteria (Table 20.6), which addressed distinctive features of pediatric NMOSD [44]. The current diagnostic criteria divide NMOSD into two major subtypes based on the serum AQP4-IgG status. The IPND recommended the current criteria also be applied

Table 20.6 2015 NMOSD diagnostic criteria [44]

\begin{tabular}{|c|c|}
\hline $\begin{array}{l}\text { A. NMOSD with } \\
\text { AQP4-IgG }\end{array}$ & $\begin{array}{l}\text { 1. } 1 \text { Core clinical characteristic } \\
\text { 2. Positive AQP4-IgG testing using the best available } \\
\text { method } \\
\text { 3. Exclusion of alternative diagnoses }\end{array}$ \\
\hline $\begin{array}{l}\text { B. NMOSD without } \\
\text { AQP4-IgG or with } \\
\text { unknown AQP4-IgG } \\
\text { status }\end{array}$ & $\begin{array}{l}\text { 1. } \geq 2 \text { Core clinical characteristics occurring as a result of } \\
\geq 1 \text { clinical attacks and meeting all of the following: } \\
\text { (a) At least one clinical characteristic: Must be optic } \\
\text { neuritis, LETM, or area postrema syndrome } \\
\text { (b) Dissemination in space ( } \geq 2 \text { different core clinical } \\
\text { characteristics) } \\
\text { (c) Fulfillment of additional MRI requirements } \\
\text { 2. Negative tests for AQP4-IgG using the best available } \\
\text { method or testing unavailable } \\
\text { 3. Exclusion of alternative diagnoses }\end{array}$ \\
\hline $\begin{array}{l}\text { C. Core clinical } \\
\text { characteristics }\end{array}$ & $\begin{array}{l}\text { 1. Optic neuritis } \\
\text { 2. Acute myelitis } \\
\text { 3. Area postrema syndrome } \\
\text { 4. Acute brainstem syndrome } \\
\text { 5. Symptomatic narcolepsy or acute diencephalic syndrome } \\
\text { with typical diencephalic MRI lesions } \\
\text { 6. Symptomatic cerebral syndrome with typical brain } \\
\text { lesions }\end{array}$ \\
\hline \multicolumn{2}{|l|}{$\begin{array}{l}\text { D. Additional MRI } \\
\text { requirements }\end{array}$} \\
\hline 1. Acute optic neuritis & $\begin{array}{l}\text { (a) Brain MRI normal or showing nonspecific white matter } \\
\text { lesions } \\
\text { (b) Optic nerve MRI with T2-hyperintense or T1-weighted } \\
\text { gadolinium-enhancing lesion extending over } 0.1 / 2 \text { optic } \\
\text { nerve length or involving optic chiasm }\end{array}$ \\
\hline 2. Acute myelitis & $\begin{array}{l}\text { Requires intramedullary MRI lesion extending over three } \\
\text { contiguous segments (LETM) or } \geq 3 \text { contiguous segments of } \\
\text { spinal cord atrophy in patients with history compatible with } \\
\text { acute myelitis }\end{array}$ \\
\hline $\begin{array}{l}\text { 3. Area postrema } \\
\text { syndrome }\end{array}$ & Requires associated dorsal medulla/area postrema lesions \\
\hline $\begin{array}{l}\text { 4. Acute brainstem } \\
\text { syndrome }\end{array}$ & Requires associated periependymal brainstem lesions \\
\hline
\end{tabular}


to the pediatric population, but with some minor modifications. This includes less specificity of LETM, as this can also be observed in pediatric patients with MS and ADEM, also acknowledging that AQP4-IgG is rarely positive in monophasic LETM in children. The new criteria aim to facilitate earlier and more accurate diagnosis of patients with NMOSD. This is especially important for AQP4-IgG-seronegative cases where detailed clinical, neuroimaging, and laboratory descriptions of patients will be necessary to better characterize this heterogeneous population.

\subsubsection{Clinical Features and Outcome}

Clinical features at onset include ON (most often bilateral), LETM, area postrema syndrome (intractable hiccups, nausea/vomiting), brainstem and diencephalic syndromes such as narcolepsy/hypersomnolence (Table 20.6). In a study from the Mayo Clinic with 48 children with AQP4-IgG-positive NMOSD, at least one episode of ON or transverse myelitis was seen in $83 \%$ and $78 \%$ of children, respectively. Additionally, $45 \%$ of the cohort had other symptoms such as encephalopathy, seizures, ophthalmoparesis, ataxia, or area postrema syndrome [49]. This study also reported coexisting autoimmune disorders in $42 \%$ of their pediatric cohort (SLE, Sjögren syndrome, juvenile rheumatoid arthritis, Graves' disease).

A recent prospective multicenter study compared the clinical features of pediatric NMOSD to other pediatric demyelinating diseases and validated the new 2015 IPND diagnostic criteria in children [50]. Of 38 pediatric NMO cases, $97 \%$ met the revised 2015 IPND diagnostic criteria. The mean age at onset was $10.2 \pm 4.7$ years. Serum or CSF NMO IgG was positive in $65 \%$ of NMO cases on initial presentation; however, a few cases became seropositive within 3 years of disease onset, supporting the notion that repeat testing up to 3-4 years should be considered in patients with a high likelihood of NMOSD. Moreover, there were no distinctive clinical features that set apart seropositive versus seronegative NMOSD patients besides a predominance of seropositivity in African-Americans compared to Caucasians.

The course of NMO is characterized by a high relapse rate with accumulation of neurologic disability [46]. One study comparing 12 individuals with pediatriconset NMOSD to those with adult onset NMOSD demonstrated a longer time to irreversible disability in those with pediatric onset disease but greater levels of visual impairment [51].

\subsubsection{Preventative Therapy for NMOSD in Children}

Acute treatment follows the same algorithm discussed in Sect. 20.6. Additionally, information on three agents has been published in relation to pediatric-onset NMOSD.

- Azathioprine (AZA): Recommended dose: $2-3 \mathrm{mg} / \mathrm{kg} / \mathrm{day}$. AZA is a prodrug form of 6-mercaptopurine (6-MP), which works as a purine antagonist that gives negative feedback on purine metabolism and inhibits DNA and RNA synthesis. Its use is associated with relapse rate reduction in children, with $60 \%$ remaining relapse-free for 18 months [52]. 
- Rituximab (RTX): Recommended dose: $375 \mathrm{mg} / \mathrm{m}^{2}$ once weekly for 4 weeks or $500 \mathrm{mg} / \mathrm{m}^{2}$ once, then 2 weeks later. RTX is a monoclonal antibody directed against the CD20 antigen. Use in the pediatric population is well described. A multicenter retrospective study of 16 children with NMOSD receiving more than two rituximab courses and followed for 6 years showed significant reduction of annualized relapse rate pre- and post-rituximab $(p=0.003)$. A close monitoring of CD19 (+) B cells is suggested, as B cell repopulation creates a risk of relapse [53]. A case series of youth with NMOSD receiving rituximab as a first-line therapy experienced complete cessation of disease activity and stabilization of neurologic disability [54].

Mycophenolate Mofetil (MMF): Recommended dose: $2000 \mathrm{mg} / \mathrm{day}$. MMF is a prodrug that inhibits the proliferation of $\mathrm{B}$ and $\mathrm{T}$ lymphocytes. Retrospective studies including children have shown that MMF is effective in reducing relapse frequency and improving disability [55].

\subsubsection{Pediatric Multiple Sclerosis}

Pediatric MS, defined as the onset of MS before the age of 18, is seen in 5\% of MS patients, with almost three-quarters (72\%) experiencing their first symptoms after the age of 12 [56-58]. The prevalence of pediatric MS is $1.35-2.5$ per 100,000 children [57] and the female-to-male ratio is 2.8:1.

\subsubsection{Diagnosis}

Diagnostic criteria for pediatric MS, based on clinical and MRI features, which support the presence of dissemination of MS events in time and space, are outlined below [32]:

- Two or more nonencephalopathic (i.e., unlike acute disseminated encephalomyelitis or ADEM), clinical central nervous system (CNS) events with presumed inflammatory cause, separated by more than 30 days and involving more than one area of the CNS.

- One nonencephalopathic episode typical of MS, which is associated with MRI findings consistent with the 2010 McDonald criteria (Table 20.5) for dissemination in space (DIS) and in which a follow-up MRI shows at least one new enhancing or nonenhancing lesion consistent with criteria for dissemination in time (DIT).

- One ADEM attack followed by a nonencephalopathic clinical event, 3 or more months after symptom onset, which is associated with new MRI lesions that fulfill the $2010 \mathrm{McD}$ onald dissemination in space criteria.

- A first, single, acute event that does not meet the ADEM criteria and where MRI findings are consistent with the 2010 McDonald criteria for dissemination in space and dissemination in time (applies only to children $\geq 12$ years). 
MRI is an important tool in the diagnosis of demyelinating syndromes [59] (Table 20.5). The criterion of dissemination in space (DIS) in both pediatric and adult patients with MS can be met by the presence of at least one lesion in at least two of four typical white matter locations, including juxtacortical, periventricular, infratentorial, and spinal cord. In patients presenting with a spinal cord or brainstem syndrome, these symptomatic lesions do not count toward the MRI lesions. Dissemination in time (DIT) in older patients (older than 12 years of age) can be met at the time of a baseline scan, provided that there is evidence of both a gadoliniumenhancing and nonenhancing clinically silent lesion. Radiologically isolated syndrome (RIS) symptoms in which MRI features consistent with MS are present in the absence of clinical symptoms do not satisfy the diagnostic criteria for MS.

\subsubsection{Clinical Features and Course of Pediatric MS}

Clinical features of MS include visual loss, ataxia, diplopia, long-tract signs (paresthesias, weakness), urinary symptoms, and cranial nerve palsies. Older children mostly present with monofocal symptoms, whereas in younger children demyelinating events are mostly polyfocal and can be associated with encephalopathy, as described earlier in Sect. 20.7. A European observational study of 394 children with pediatric-onset MS found that children were more likely than adults to present with isolated optic neuritis, an isolated brainstem syndrome, or symptoms of encephalopathy (i.e., headache, vomiting, seizure, or altered consciousness) [60].

A relapsing course is seen in $98 \%$ of pediatric MS cases. As in the adult population, individuals with pediatric-onset MS with a relapsing course eventually reach a stage of irreversible disability. The median time from diagnosis to this (EDSS $=4$ ) is 20 years or at 34 years of age [61]. Children who demonstrate progressive disease at onset should be investigated for alternative diagnoses (Table 20.2). Relapse rates are significantly higher in pediatric-onset MS than adult onset disease ( 0.8 in pediatriconset MS vs. 0.3 in adult onset MS, $p<0.001$ ) [62]. A short interval between the first two demyelinating episodes and incomplete recovery after the first attack have been associated with increased risk of further attacks and/or reaching a higher disability score $[63,64]$. Disease severity is currently measured by the Expanded Disability Status Scale (EDSS) that scores the disability based on the functional system scores [65]. Up to 35\% of pediatric MS patients have some identifiable cognitive dysfunction at the time of diagnosis. Younger age at onset, higher EDSS score, and number of relapses together with low scores on measures of intellectual function predict greater impairment across cognitive domains [66].

\subsubsection{Laboratory Investigations}

Specific CSF findings are not required for MS diagnosis. CSF pleocytosis (lymphocytic) has been described in 52-66\% of pediatric MS patients, with a white blood cell (WBC) count of $<60$ cells $/ \mathrm{mL}$. Oligoclonal bands and elevated $\mathrm{IgG}$ index may be seen in approximately two-thirds (63\% and 68\%, respectively) of children older than 11 with MS, and fewer younger children (43\% and 35\%) [67]. Notably, however, OCBs are nonspecific markers and may be detected in $8-15 \%$ of children with monophasic demyelinating syndromes [65]. 


\subsubsection{Treatment in Pediatric MS}

\section{Lifestyle Modifications}

Low vitamin D has been associated with increased risk of MS and an increased relapse rate [23, 68]. Patients usually require $800-3000$ IU oral vitamin D per day to achieve normal serum levels. In children, second hand smoke has been associated with an increased risk for MS [69].

\section{Disease-Modifying Therapies}

The United States Food and Drug Administration (FDA) has not approved any of the disease-modifying therapies approved for use in adult MS and for use in pediatric MS. However, a number of treatments are currently being used off-label in these children. We have provided details regarding these therapies below.

\section{First-Line Disease-Modifying Therapy}

Glatiramer acetate (GA) and interferon beta (IFN-b) have been routinely used in adults with MS for the past 15-20 years. These treatments are associated with a decrease in relapse rate of $30 \%$ [70]. There have been no randomized trials in children; however, two position papers have reported on expert consensus on the use of IFN-b and GA in pediatric patients [71, 72]. The International Pediatric Multiple Sclerosis Study Group (IPMSSG) recommends that all pediatric patients with MS should be considered for treatment with either an IFN-b or GA as first-line therapy. In the presence of inadequate treatment response or persistent side effects, transition to a different first-line therapy or escalation to a second-line therapy should be considered.

Following the IPMSSG consensus criteria, inadequate treatment response in pediatric MS is defined as [71]:

(a) Minimum time on full-dose therapy 6 months

(b) Fully compliant on treatment

(c) At least one of the following:

- Increase or no reduction in relapse rate, or new T2 or contrast-enhancing lesions on MRI from pretreatment period

- $\geq$ Two confirmed relapses (clinical or MRI relapses) within a 12-month period or less

\section{Second-Line Disease-Modifying Therapies}

At this time, there is limited information on the use of second-line MS diseasemodifying therapies for pediatric-onset multiple sclerosis (POMS). However, multiple case series have suggested safety and efficacy comparable to that seen in adult MS [73]. Fortunately, ongoing clinical trials in pediatric patients with MS evaluating newer therapies such as fingolimod, dimethyl fumarate, and teriflunomide are underway [74] (Table 20.7). Below, we have provided a summary table (Table 20.7) of currently available treatments, their side effects, and the current evidence in pediatric population. 


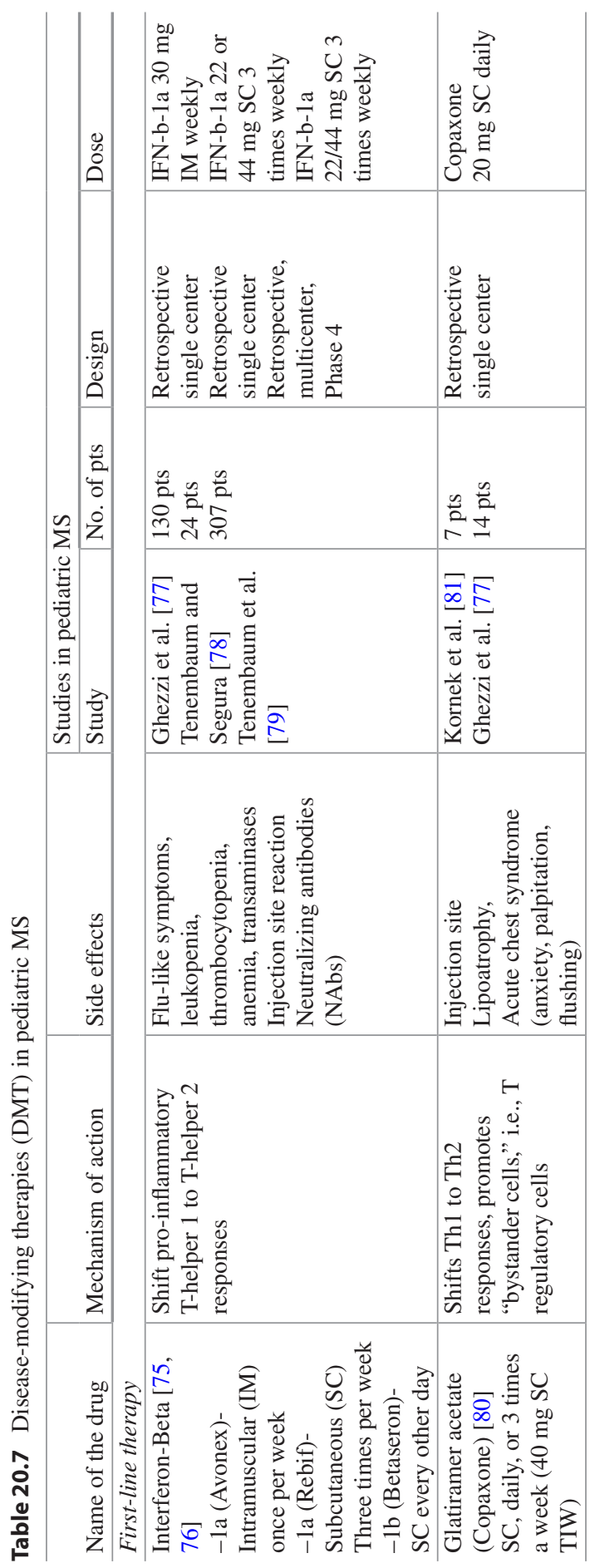




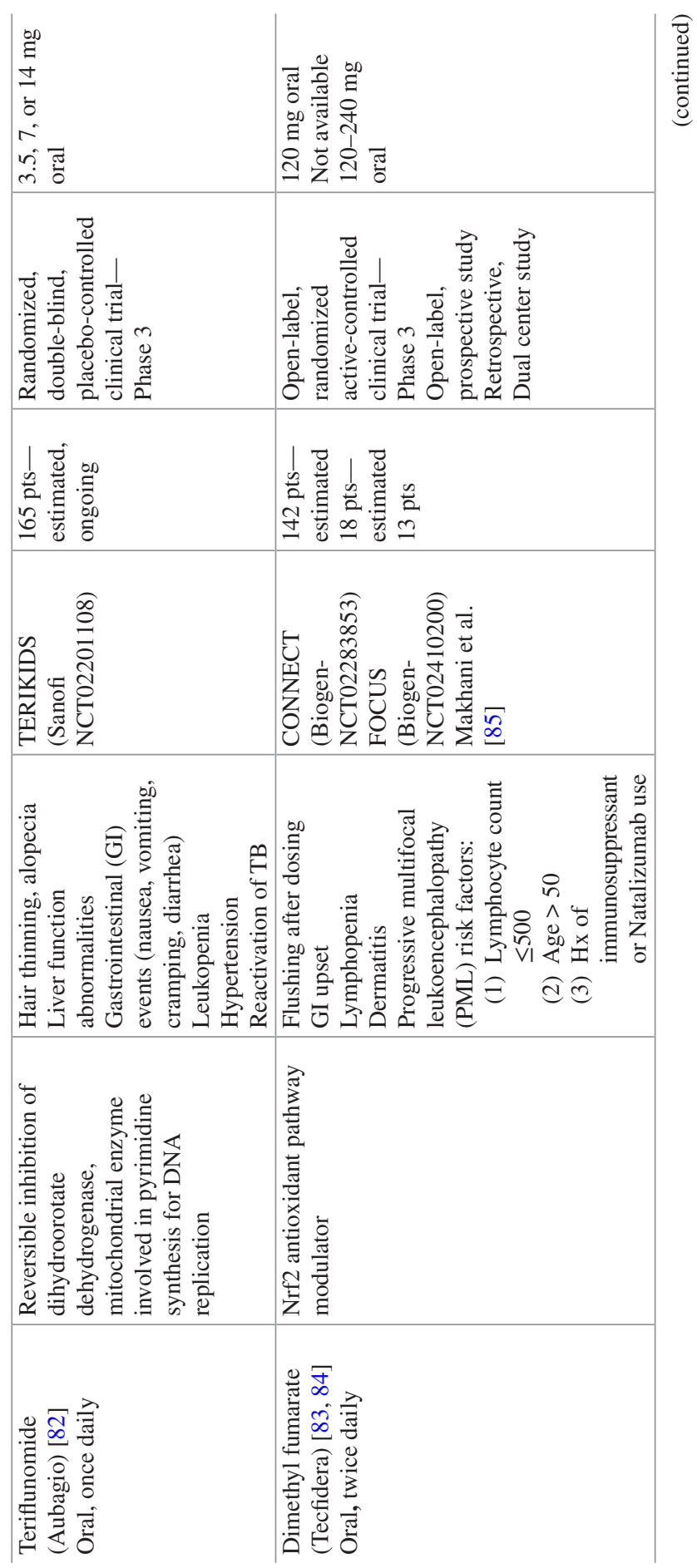




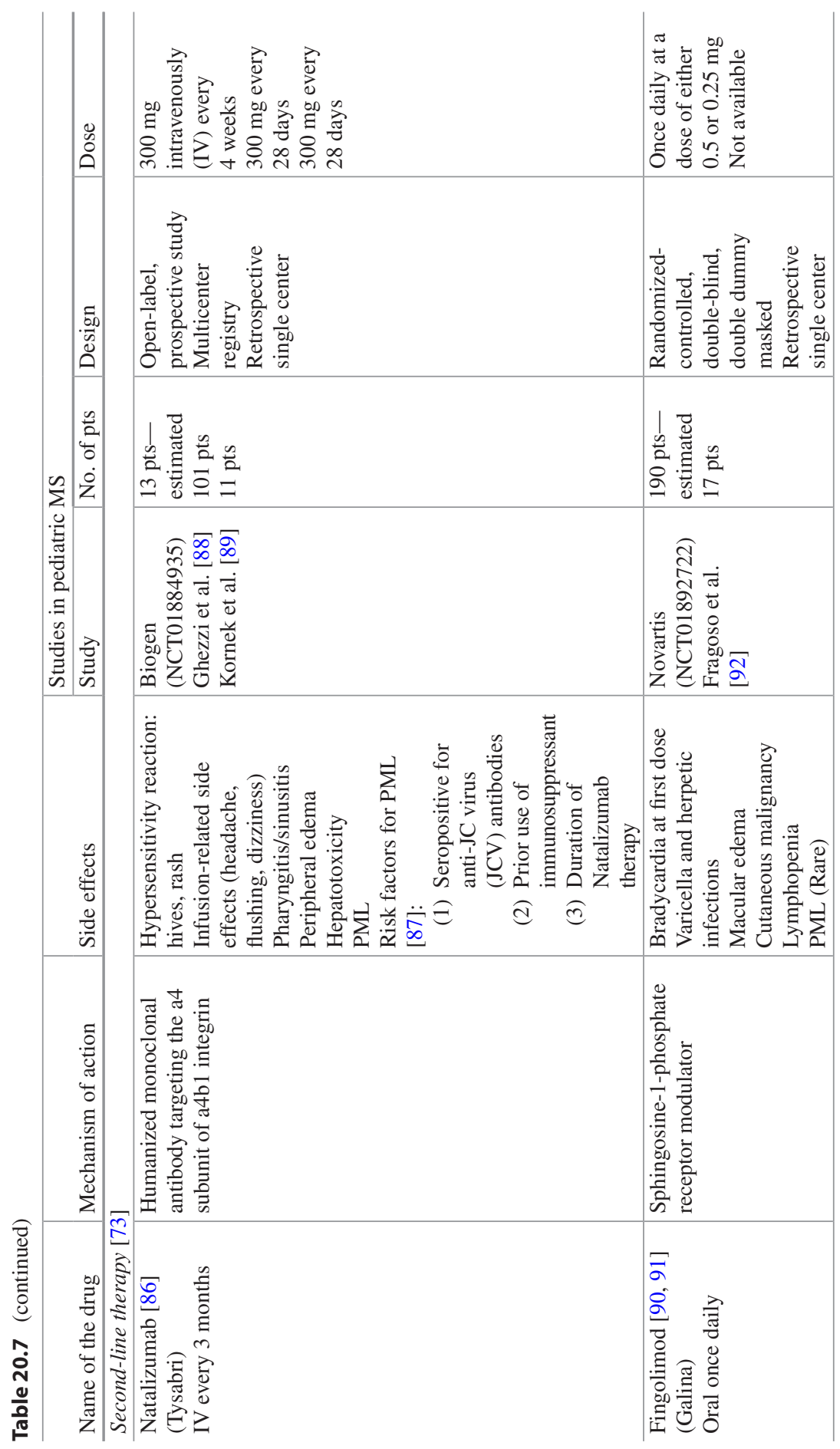




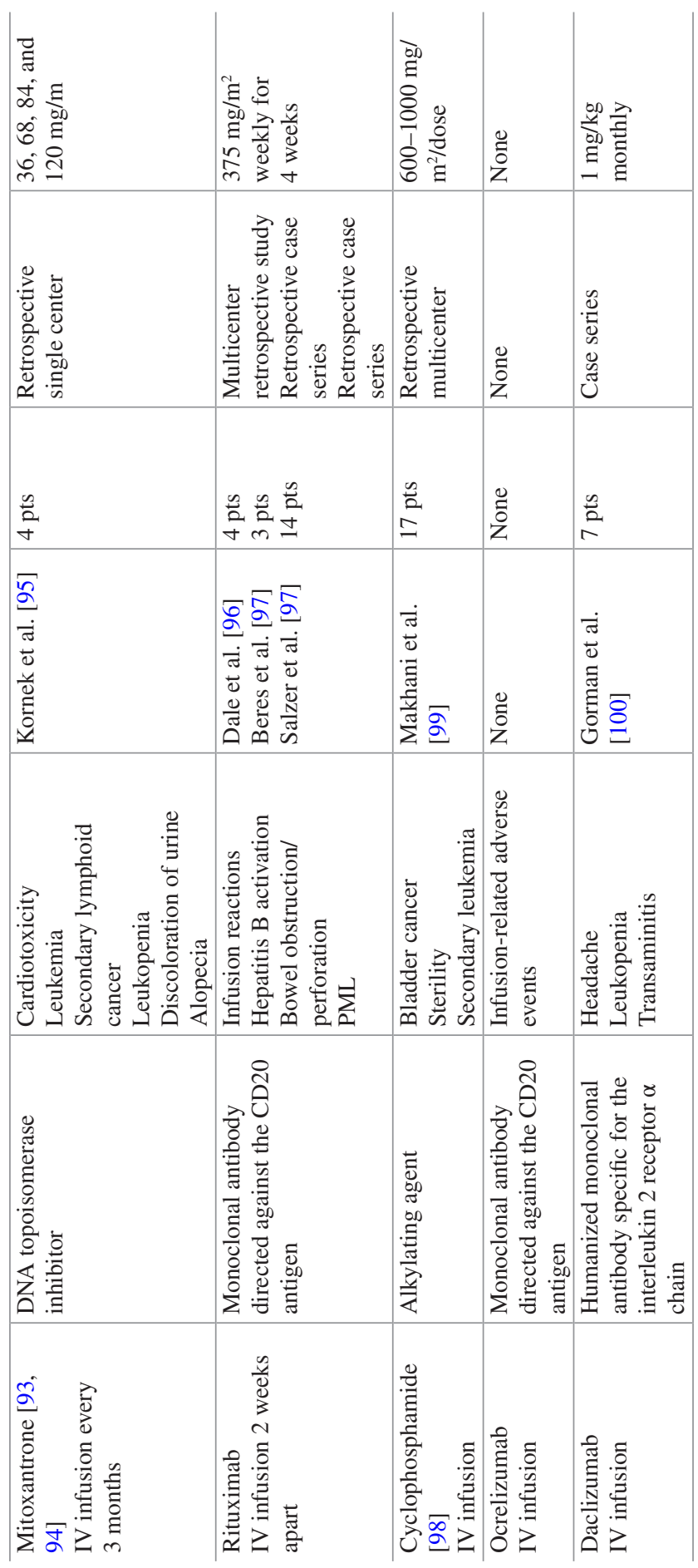




\subsection{Conclusions}

Knowledge about pediatric demyelinating disorders has grown significantly in recent years. Above, we have provided a summary of clinical features, investigations, and both acute and prophylactic therapies in these conditions. Future multiinstitutional, international collaborative studies are needed to advance knowledge regarding therapies and outcomes of these disorders.

\section{References}

1. Hintzen RQ, Dale RC, Neuteboom RF, Mar S, Banwell B. Pediatric acquired CNS demyelinating syndromes: features associated with multiple sclerosis. Neurology. 2016;87(9 Suppl 2):S67-73.

2. Yeh EA, Graves JS, Benson LA, Wassmer E, Waldman A. Pediatric optic neuritis. Neurology. 2016;87(9 Suppl 2):S53-8.

3. Wilejto M, Shroff M, Buncic JR, Kennedy J, Goia C, Banwell B. The clinical features, MRI findings, and outcome of optic neuritis in children. Neurology. 2006;67(2):258-62.

4. Lucchinetti CF, Kiers L, O'Duffy A, Gomez MR, Cross S, Leavitt JA, et al. Risk factors for developing multiple sclerosis after childhood optic neuritis. Neurology. 1997;49(5):1413-8.

5. Waldman AT, Stull LB, Galetta SL, Balcer LJ, Liu GT. Pediatric optic neuritis and risk of multiple sclerosis: meta-analysis of observational studies. J AAPOS. 2011;15(5):441-6.

6. Morales DS, Siatkowski RM, Howard CW, Warman R. Optic neuritis in children. J Pediatr Ophthalmol Strabismus. 2000;37(5):254-9.

7. Yeh EA, Marrie RA, Reginald YA, Buncic JR, Noguera AE, O’Mahony J, et al. Functionalstructural correlations in the afferent visual pathway in pediatric demyelination. Neurology. 2014;83(23):2147-52.

8. Kitley J, Leite MI, Nakashima I, Waters P, McNeillis B, Brown R, et al. Prognostic factors and disease course in aquaporin-4 antibody-positive patients with neuromyelitis optica spectrum disorder from the United Kingdom and Japan. Brain. 2012;135(Pt 6):1834-49.

9. Heussinger N, Kontopantelis E, Gburek-Augustat J, Jenke A, Vollrath G, Korinthenberg R, et al. Oligoclonal bands predict multiple sclerosis in children with optic neuritis. Ann Neurol. 2015;77(6):1076-82.

10. Deiva K, Absoud M, Hemingway C, Hernandez Y, Hussson B, Maurey H, et al. Acute idiopathic transverse myelitis in children: early predictors of relapse and disability. Neurology. 2015;84(4):341-9.

11. Thomas T, Branson HM, Verhey LH, Shroff M, Stephens D, Magalhaes S, et al. The demographic, clinical, and magnetic resonance imaging (MRI) features of transverse myelitis in children. J Child Neurol. 2012;27(1):11-21.

12. Pidcock FS, Krishnan C, Crawford TO, Salorio CF, Trovato M, Kerr DA. Acute transverse myelitis in childhood: center-based analysis of 47 cases. Neurology. 2007;68(18):1474-80.

13. Mikaeloff Y, Suissa S, Vallée L, Lubetzki C, Ponsot G, Confavreux C, et al. First episode of acute CNS inflammatory demyelination in childhood: prognostic factors for multiple sclerosis and disability. J Pediatr. 2004;144(2):246-52.

14. Wolf VL, Lupo PJ, Lotze TE. Pediatric acute transverse myelitis overview and differential diagnosis. J Child Neurol. 2012;27(11):1426-36.

15. De Goede CG, Holmes EM, Pike MG. Acquired transverse myelopathy in children in the United Kingdom—a 2 year prospective study. Eur J Paediatr Neurol. 2010;14(6):479-87.

16. Group TMCW. Proposed diagnostic criteria and nosology of acute transverse myelitis. Neurology. 2002;59(4):499-505. 
17. Mikaeloff Y, Adamsbaum C, Husson B, Vallée L, Ponsot G, Confavreux C, et al. MRI prognostic factors for relapse after acute CNS inflammatory demyelination in childhood. Brain. 2004;127(Pt 9):1942-7.

18. Banwell B, Kennedy J, Sadovnick D, Arnold DL, Magalhaes S, Wambera K, et al. Incidence of acquired demyelination of the CNS in Canadian children. Neurology. 2009;72(3):232-9.

19. Pavone P, Pettoello-Mantovano M, Le Pira A, Giardino I, Pulvirenti A, Giugno R, et al. Acute disseminated encephalomyelitis: a long-term prospective study and meta-analysis. Neuropediatrics. 2010;41(6):246-55.

20. Bale JF. Neurologic complications of immunization. J Child Neurol. 2004;19(6):405-12.

21. Yuan JL, Wang SK, Guo XJ, Hu WL. Acute disseminated encephalomyelitis following vaccination against hepatitis B in a child: a case report and literature review. Case Rep Neurol Med. 2016;2016:2401809.

22. Mikaeloff Y, Caridade G, Husson B, Suissa S, Tardieu M. Society NKSGotFN. Acute disseminated encephalomyelitis cohort study: prognostic factors for relapse. Eur J Paediatr Neurol. 2007;11(2):90-5.

23. Banwell B, Bar-Or A, Arnold DL, Sadovnick D, Narayanan S, McGowan M, et al. Clinical, environmental, and genetic determinants of multiple sclerosis in children with acute demyelination: a prospective national cohort study. Lancet Neurol. 2011;10(5):436-45.

24. Fridinger SE, Alper G. Defining encephalopathy in acute disseminated encephalomyelitis. J Child Neurol. 2014;29(6):751-5.

25. Tenembaum S, Chitnis T, Ness J, Hahn JS, Group IPMS. Acute disseminated encephalomyelitis. Neurology. 2007;68(16 Suppl 2):S23-36.

26. Niemeyer B, Niemeyer R, Borges R, Marchiori E. Acute disseminated encephalomyelitis following Zika virus infection. Eur Neurol. 2017;77(1-2):45-6.

27. Erol I, Ozkale Y, Alkan O, Alehan F. Acute disseminated encephalomyelitis in children and adolescents: a single center experience. Pediatr Neurol. 2013;49(4):266-73.

28. Patra KC, Shirolkar MS, Ghane VR. Acute disseminated encephalomyelitis: extremely rare presentation of pediatric human immunodeficiency virus infection. J Pediatr Neurosci. 2014;9(2):150-3.

29. Nakamura Y, Nakajima H, Tani H, Hosokawa T, Ishida S, Kimura F, et al. Anti-MOG antibody-positive ADEM following infectious mononucleosis due to a primary EBV infection: a case report. BMC Neurol. 2017;17(1):76.

30. Suppiej A, Manara R, De Palma L, De Grandis D, Citton V, Battistella PA. Multiphasic acute disseminated encephalomyelitis or pediatric multiple sclerosis: report of an atypical case. J Child Neurol. 2009;24(2):241-6.

31. Hynson JL, Kornberg AJ, Coleman LT, Shield L, Harvey AS, Kean MJ. Clinical and neuroradiologic features of acute disseminated encephalomyelitis in children. Neurology. 2001;56(10):1308-12.

32. Krupp LB, Tardieu M, Amato MP, Banwell B, Chitnis T, Dale RC, et al. International Pediatric Multiple Sclerosis Study Group criteria for pediatric multiple sclerosis and immune-mediated central nervous system demyelinating disorders: revisions to the 2007 definitions. Mult Scler. 2013;19(10):1261-7.

33. Gupte G, Stonehouse M, Wassmer E, Coad NA, Whitehouse WP. Acute disseminated encephalomyelitis: a review of 18 cases in childhood. J Paediatr Child Health. 2003;39(5):336-42.

34. Franciotta D, Columba-Cabezas S, Andreoni L, Ravaglia S, Jarius S, Romagnolo S, et al. Oligoclonal IgG band patterns in inflammatory demyelinating human and mouse diseases. $\mathrm{J}$ Neuroimmunol. 2008;200(1-2):125-8.

35. Sloka JS, Stefanelli M. The mechanism of action of methylprednisolone in the treatment of multiple sclerosis. Mult Scler. 2005;11(4):425-32.

36. Beck RW, Cleary PA, Anderson MM, Keltner JL, Shults WT, Kaufman DI, et al. A randomized, controlled trial of corticosteroids in the treatment of acute optic neuritis. The Optic Neuritis Study Group. N Engl J Med. 1992;326(9):581-8. 
37. Defresne P, Meyer L, Tardieu M, Scalais E, Nuttin C, De Bont B, et al. Efficacy of high dose steroid therapy in children with severe acute transverse myelitis. J Neurol Neurosurg Psychiatry. 2001;71(2):272-4.

38. Mathy I, Gille M, Van Raemdonck F, Delbecq J, Depré A. Neurological complications of intravenous immunoglobulin (IVIg) therapy: an illustrative case of acute encephalopathy following IVIg therapy and a review of the literature. Acta Neurol Belg. 1998;98(4):347-51.

39. Lehmann HC, Hartung HP, Hetzel GR, Stüve O, Kieseier BC. Plasma exchange in neuroimmunological disorders: Part 1: rationale and treatment of inflammatory central nervous system disorders. Arch Neurol. 2006;63(7):930-5.

40. Weinshenker BG, O'Brien PC, Petterson TM, Noseworthy JH, Lucchinetti CF, Dodick DW, et al. A randomized trial of plasma exchange in acute central nervous system inflammatory demyelinating disease. Ann Neurol. 1999;46(6):878-86.

41. Cortese I, Chaudhry V, So YT, Cantor F, Cornblath DR, Rae-Grant A. Evidence-based guideline update: plasmapheresis in neurologic disorders: report of the therapeutics and technology assessment subcommittee of the American Academy of Neurology. Neurology. 2011;76(3):294-300.

42. Espinosa G, Mendizábal A, Mínguez S, Ramo-Tello C, Capellades J, Olivé A, et al. Transverse myelitis affecting more than 4 spinal segments associated with systemic lupus erythematosus: clinical, immunological, and radiological characteristics of 22 patients. Semin Arthritis Rheum. 2010;39(4):246-56.

43. Darabi K, Abdel-Wahab O, Dzik WH. Current usage of intravenous immune globulin and the rationale behind it: the Massachusetts General Hospital data and a review of the literature. Transfusion. 2006;46(5):741-53.

44. Wingerchuk DM, Banwell B, Bennett JL, Cabre P, Carroll W, Chitnis T, et al. International consensus diagnostic criteria for neuromyelitis optica spectrum disorders. Neurology. 2015;85(2):177-89.

45. Wingerchuk DM, Lennon VA, Lucchinetti CF, Pittock SJ, Weinshenker BG. The spectrum of neuromyelitis optica. Lancet Neurol. 2007;6(9):805-15.

46. Banwell B, Tenembaum S, Lennon VA, Ursell E, Kennedy J, Bar-Or A, et al. Neuromyelitis optica-IgG in childhood inflammatory demyelinating CNS disorders. Neurology. 2008;70(5):344-52.

47. Zhou L, Huang Y, Li H, Fan J, Zhangbao J, Yu H, et al. MOG-antibody associated demyelinating disease of the CNS: a clinical and pathological study in Chinese Han patients. J Neuroimmunol. 2017;305:19-28.

48. Kitley J, Waters P, Woodhall M, Leite MI, Murchison A, George J, et al. Neuromyelitis optica spectrum disorders with aquaporin-4 and myelin-oligodendrocyte glycoprotein antibodies: a comparative study. JAMA Neurol. 2014;71(3):276-83.

49. McKeon A, Lennon VA, Lotze T, Tenenbaum S, Ness JM, Rensel M, et al. CNS aquaporin-4 autoimmunity in children. Neurology. 2008;71(2):93-100.

50. Chitnis T, Ness J, Krupp L, Waubant E, Hunt T, Olsen CS, et al. Clinical features of neuromyelitis optica in children: US Network of Pediatric MS Centers report. Neurology. 2016;86(3):245-52.

51. Granerod J, Ambrose HE, Davies NW, Clewley JP, Walsh AL, Morgan D, et al. Causes of encephalitis and differences in their clinical presentations in England: a multicentre, population-based prospective study. Lancet Infect Dis. 2010;10(12):835-44.

52. Elsone L, Kitley J, Luppe S, Lythgoe D, Mutch K, Jacob S, et al. Long-term efficacy, tolerability and retention rate of azathioprine in 103 aquaporin- 4 antibody-positive neuromyelitis optica spectrum disorder patients: a multicentre retrospective observational study from the UK. Mult Scler. 2014;20(11):1533-40.

53. Nosadini M, Alper G, Riney CJ, Benson LA, Mohammad SS, Ramanathan S, et al. Rituximab monitoring and redosing in pediatric neuromyelitis optica spectrum disorder. Neurol Neuroimmunol Neuroinflamm. 2016;3(1):e188. 
54. Longoni G, Banwell B, Filippi M, Yeh EA. Rituximab as a first-line preventive treatment in pediatric NMOSDs: Preliminary results in 5 children. Neurol Neuroimmunol Neuroinflamm. 2014;1(4):e46.

55. Jacob A, Matiello M, Weinshenker BG, Wingerchuk DM, Lucchinetti C, Shuster E, et al. Treatment of neuromyelitis optica with mycophenolate mofetil: retrospective analysis of 24 patients. Arch Neurol. 2009;66(9):1128-33.

56. Chitnis T. Pediatric demyelinating diseases. Continuum (Minneap Minn). 2013;19(4 Multiple Sclerosis): $1023-45$.

57. Gadoth N. Multiple sclerosis in children. Brain Dev. 2003;25(4):229-32.

58. Alper G, Heyman R, Wang L. Multiple sclerosis and acute disseminated encephalomyelitis diagnosed in children after long-term follow-up: comparison of presenting features. Dev Med Child Neurol. 2009;51(6):480-6.

59. Polman CH, Reingold SC, Banwell B, Clanet M, Cohen JA, Filippi M, et al. Diagnostic criteria for multiple sclerosis: 2010 revisions to the McDonald criteria. Ann Neurol. 2011;69(2):292-302.

60. Renoux C, Vukusic S, Confavreux C. The natural history of multiple sclerosis with childhood onset. Clin Neurol Neurosurg. 2008;110(9):897-904.

61. Renoux C, Vukusic S, Mikaeloff Y, Edan G, Clanet M, Dubois B, et al. Natural history of multiple sclerosis with childhood onset. N Engl J Med. 2007;356(25):2603-13.

62. Benson LA, Healy BC, Gorman MP, Baruch NF, Gholipour T, Musallam A, et al. Elevated relapse rates in pediatric compared to adult MS persist for at least 6 years. Mult Scler Relat Disord. 2014;3(2):186-93.

63. Gorman MP, Healy BC, Polgar-Turcsanyi M, Chitnis T. Increased relapse rate in pediatriconset compared with adult-onset multiple sclerosis. Arch Neurol. 2009;66(1):54-9.

64. Waldman A, Ghezzi A, Bar-Or A, Mikaeloff Y, Tardieu M, Banwell B. Multiple sclerosis in children: an update on clinical diagnosis, therapeutic strategies, and research. Lancet Neurol. 2014;13(9):936-48.

65. Huppke B, Ellenberger D, Rosewich H, Friede T, Gärtner J, Huppke P. Clinical presentation of pediatric multiple sclerosis before puberty. Eur J Neurol. 2014;21(3):441-6.

66. Amato MP, Goretti B, Ghezzi A, Lori S, Zipoli V, Moiola L, et al. Cognitive and psychosocial features in childhood and juvenile MS: two-year follow-up. Neurology. 2010;75(13):1134-40.

67. Chabas D, Ness J, Belman A, Yeh EA, Kuntz N, Gorman MP, et al. Younger children with MS have a distinct CSF inflammatory profile at disease onset. Neurology. 2010;74(5):399-405.

68. Mowry EM, Krupp LB, Milazzo M, Chabas D, Strober JB, Belman AL, et al. Vitamin D status is associated with relapse rate in pediatric-onset multiple sclerosis. Ann Neurol. 2010;67(5):618-24.

69. Féron F. Vitamin D and multiple sclerosis: what are the guidelines for a reliable clinical trial? Expert Rev Neurother. 2010;10(9):1375-8.

70. Giovannoni G, Southam E, Waubant E. Systematic review of disease-modifying therapies to assess unmet needs in multiple sclerosis: tolerability and adherence. Mult Scler. 2012;18(7):932-46.

71. Chitnis T, Tenembaum S, Banwell B, Krupp L, Pohl D, Rostasy K, et al. Consensus statement: evaluation of new and existing therapeutics for pediatric multiple sclerosis. Mult Scler. 2012;18(1):116-27.

72. Goodin DS, Frohman EM, Garmany GP, Halper J, Likosky WH, Lublin FD, et al. Disease modifying therapies in multiple sclerosis: report of the Therapeutics and Technology Assessment Subcommittee of the American Academy of Neurology and the MS Council for Clinical Practice Guidelines. Neurology. 2002;58(2):169-78.

73. Yeh EA, Waubant E, Krupp LB, Ness J, Chitnis T, Kuntz N, et al. Multiple sclerosis therapies in pediatric patients with refractory multiple sclerosis. Arch Neurol. 2011;68(4):437-44.

74. Chitnis T, Ghezzi A, Bajer-Kornek B, Boyko A, Giovannoni G, Pohl D. Pediatric multiple sclerosis: escalation and emerging treatments. Neurology. 2016;87(9 Suppl 2):S103-9. 
75. Group IMSS. Interferon beta-lb is effective in relapsing-remitting multiple sclerosis. I. Clinical results of a multicenter, randomized, double-blind, placebo-controlled trial. 1993 [classical article]. Neurology. 2001;57(12 Suppl 5):S3-9.

76. Paty DW, Li DK, UBC MS/MRI Study Group and IFNB Multiple Sclerosis Study Group. Interferon beta-lb is effective in relapsing-remitting multiple sclerosis. II. MRI analysis results of a multicenter, randomized, double-blind, placebo-controlled trial. 1993 [classical article]. Neurology. 2001;57(12 Suppl 5):S10-5.

77. Ghezzi A, Amato MP, Annovazzi P, Capobianco M, Gallo P, La Mantia L, et al. Long-term results of immunomodulatory treatment in children and adolescents with multiple sclerosis: the Italian experience. Neurol Sci. 2009;30(3):193-9.

78. Tenembaum SN, Segura MJ. Interferon beta-1a treatment in childhood and juvenile-onset multiple sclerosis. Neurology. 2006;67(3):511-3.

79. Tenembaum SN, Banwell B, Pohl D, Krupp LB, Boyko A, Meinel M, et al. Subcutaneous interferon Beta-1a in pediatric multiple sclerosis: a retrospective study. J Child Neurol. 2013;28(7):849-56.

80. Comi G, Martinelli V, Rodegher M, Moiola L, Bajenaru O, Carra A, et al. Effect of glatiramer acetate on conversion to clinically definite multiple sclerosis in patients with clinically isolated syndrome (PreCISe study): a randomised, double-blind, placebo-controlled trial. Lancet. 2009;374(9700):1503-11.

81. Kornek B, Bernert G, Balassy C, Geldner J, Prayer D, Feucht M. Glatiramer acetate treatment in patients with childhood and juvenile onset multiple sclerosis. Neuropediatrics. 2003;34(3):120-6.

82. O'Connor P, Wolinsky JS, Confavreux C, Comi G, Kappos L, Olsson TP, et al. Randomized trial of oral teriflunomide for relapsing multiple sclerosis. N Engl J Med. 2011;365(14):1293-303.

83. Fox RJ, Miller DH, Phillips JT, Hutchinson M, Havrdova E, Kita M, et al. Placebocontrolled phase 3 study of oral BG-12 or glatiramer in multiple sclerosis. N Engl J Med. 2012;367(12):1087-97.

84. Gold R, Kappos L, Arnold DL, Bar-Or A, Giovannoni G, Selmaj K, et al. Placebocontrolled phase 3 study of oral BG-12 for relapsing multiple sclerosis. N Engl J Med. 2012;367(12):1098-107.

85. Makhani N, Schreiner T. Oral dimethyl fumarate in children with multiple sclerosis: a dualcenter study. Pediatr Neurol. 2016;57:101-4.

86. Polman CH, O'Connor PW, Havrdova E, Hutchinson M, Kappos L, Miller DH, et al. A randomized, placebo-controlled trial of natalizumab for relapsing multiple sclerosis. N Engl J Med. 2006;354(9):899-910.

87. Kleinschmidt-DeMasters BK, Tyler KL. Progressive multifocal leukoencephalopathy complicating treatment with natalizumab and interferon beta-1a for multiple sclerosis. $\mathrm{N}$ Engl $\mathrm{J}$ Med. 2005;353(4):369-74.

88. Ghezzi A, Moiola L, Pozzilli C, Brescia-Morra V, Gallo P, Grimaldi LM, et al. Natalizumab in the pediatric MS population: results of the Italian registry. BMC Neurol. 2015;15:174.

89. Kornek B, Aboul-Enein F, Rostasy K, Milos RI, Steiner I, Penzien J, et al. Natalizumab therapy for highly active pediatric multiple sclerosis. JAMA Neurol. 2013;70(4):469-75.

90. Kappos L, Radue EW, O'Connor P, Polman C, Hohlfeld R, Calabresi P, et al. A placebocontrolled trial of oral fingolimod in relapsing multiple sclerosis. $\mathrm{N}$ Engl $\mathrm{J}$ Med. 2010;362(5):387-401.

91. Devonshire V, Havrdova E, Radue EW, O’Connor P, Zhang-Auberson L, Agoropoulou C, et al. Relapse and disability outcomes in patients with multiple sclerosis treated with fingolimod: subgroup analyses of the double-blind, randomised, placebo-controlled FREEDOMS study. Lancet Neurol. 2012;11(5):420-8.

92. Fragoso YD, Alves-Leon SV, Barreira AA, Callegaro D, Brito Ferreira ML, Finkelsztejn A, et al. Fingolimod prescribed for the treatment of multiple sclerosis in patients younger than age 18 years. Pediatr Neurol. 2015;53(2):166-8. 
93. Marriott JJ, Miyasaki JM, Gronseth G, O'Connor PW. Neurology TaTASotAAo. evidence report: the efficacy and safety of mitoxantrone (Novantrone) in the treatment of multiple sclerosis: report of the therapeutics and technology assessment subcommittee of the American Academy of Neurology. Neurology. 2010;74(18):1463-70.

94. Hartung HP, Gonsette R, König N, Kwiecinski H, Guseo A, Morrissey SP, et al. Mitoxantrone in progressive multiple sclerosis: a placebo-controlled, double-blind, randomised, multicentre trial. Lancet. 2002;360(9350):2018-25.

95. Kornek B, Bernert G, Rostasy K, Mlczoch E, Feucht M, Prayer D, et al. Long-term followup of pediatric patients treated with mitoxantrone for multiple sclerosis. Neuropediatrics. 2011;42(1):7-12.

96. Dale RC, Brilot F, Duffy LV, Twilt M, Waldman AT, Narula S, et al. Utility and safety of rituximab in pediatric autoimmune and inflammatory CNS disease. Neurology. 2014;83(2):142-50.

97. Beres SJ, Graves J, Waubant E. Rituximab use in pediatric central demyelinating disease. Pediatr Neurol. 2014;51(1):114-8.

98. Weiner HL, Mackin GA, Orav EJ, Hafler DA, Dawson DM, LaPierre Y, et al. Intermittent cyclophosphamide pulse therapy in progressive multiple sclerosis: final report of the Northeast Cooperative Multiple Sclerosis Treatment Group. Neurology. 1993;43(5):910-8.

99. Makhani N, Gorman MP, Branson HM, Stazzone L, Banwell BL, Chitnis T. Cyclophosphamide therapy in pediatric multiple sclerosis. Neurology. 2009;72(24):2076-82.

100. Gorman MP, Tillema JM, Ciliax AM, Guttmann CR, Chitnis T. Daclizumab use in patients with pediatric multiple sclerosis. Arch Neurol. 2012;69(1):78-81. 